\title{
Dynamics of a Tasmanian cushion heath community
}

\author{
Gibson, Neil ${ }^{1} \&$ Kirkpatrick, J. B. \\ Geography Department, University of Tasmania, GPO Box 252C, Hobant, Tasmania, Australia 7001; \\ 'Present address: Westem Australian Wildlife Research Centre, PO Box 5l, Wanneroo W.A., Australia 6065; \\ $F a x+6193061641$
}

\begin{abstract}
Little is known of the dynamics of the alpine cushion plant communities of Tasmania. The present study investigates the nature of the short ( $5 \mathrm{yr})$ and long ( 850 yr plus) term dynamics within one such community at Newdegate Pass, Tasmania. This involved observations of permanent plots, quadrat sampling of cushion heath in different stages of a secondary succession and cuticular analysis of a corc through the cushion peat. Data from the peat core showed the continued presence of the cushion heath community at this site for at least $850 \mathrm{yr}$, while the regeneration patterns indicated community composition was largely achieved by species accumulation rather than species replacement. Over a 5-yr period there was little or no change in total percentage cover yet a surprisingly high degree of interspecific competition for space in areas of completc plant cover. These observations best fit non equilibrium models of community succession and stability.
\end{abstract}

Keywords: Alpine; Long-tern dynamics; Macrofossil; Plant dynamics; Succession; Succession model.

Nomenclature: Buchanan, McGeary-Brown \& Orchard (1989) for plant species (unless otherwise indicated); Kirkpantrick (1983) for vegetation terminology.

\section{Introduction}

Cushion plants are a common component of the alpine vegetation of Tasmania (Kirkpatrick, Minchin \& Davies 1985). These plants grow either individually or coalesce to form extensive mosaics, and occasionally form extensive string fens (Kirkpatrick \& Gibson 1984). A model for the formation of the alpine string fens of Newdegate Pass, Tasmania has been proposed (Kirkpatrick \& Gibson 1984) and some data are available on growth rates of these communities (Gibson 1990). These data suggest that they are very slow growing and can occupy sites for long time periods. To date the study of the dynamics of these, and other, alpine communities have received little attention in Tasmania.

It is the aim of this paper to investigate the short and long-term changes in the cushion heath of Newdegate
Pass, Tasmania. This was done by analysis of changes in cover values over a five year period, by an investigation of a revegetation of a series of drained pool floors and by the analysis of plant cuticle from a $1-\mathrm{m}$ peat profile.

\section{The study area}

The study site is situated at Newdegate Pass ( $1300 \mathrm{~m}$ a.s.I., $42^{\circ} 40^{\prime} \mathrm{S}, 146^{\circ} 45^{\prime} \mathrm{E}$, in an area of cushion heathstring fen. This area is ca. 5 ha in extent and comprises a mosaic of coniferous heath, cushion heath, lichen covered dolerite boulders and numerous pools in a wind exposed saddle above the climatic treeline (Kirkpatrick \& Gibson 1984). These pools have been formed by interaction of topography and the vertical growth of the cushion species (Kirkpatrick \& Gibson 1984).

$\mathrm{Ca} .10 \%$ of the 300 pools at the study site have undergone partial or complete drainage. These are at various stages of recolonization. The lowering of the water table by $15 \mathrm{~cm}$ or more in the peat on the margins of the drained pools has resulted in extensive necrotic areas. Thus there is cushion heath characterized by low plant cover on thin soils, a closed cushion heath consisting largely of mixtures of four cushion taxa (Fig. 1) with low cover of trailing shrubs, herbs, moss and lichens, and degenerating cushion heath on oxidizing peat soils (Kirkpatrick \& Gibson 1984).

\section{Methods}

\section{Short-tern dynamics}

Transects of five (or six) contiguous $35 \mathrm{~cm} \times 35 \mathrm{~cm}$ quadrats were located in each of the three different types described above. Two transects (site 1 and 2) were laid out in areas of low plant cover, one on a very rocky substrate in a drainage line and a second on thin mineral soils at the base of a small snow patch. Both sites become very dry after extended periods without rain.

A further two transects (sites 3 and 4) were established in closed cushion heath. One area was dominated 
by Abrotanella forsteroides and Pterygopappus lawrencei and the other was dominated by Dracophyllum minimum and Donatia novae-zelandiae.

The final three transects (sites 5,6 and 7) were located in degenerating cushion heath. Site 5 was 10cated above a drained pool where the water table had dropped some $20-30 \mathrm{~cm}$ (estimated from previous pool depth). Site 6 was located in an area where the water table height had been distupted by encroachment by the 1967 fire and subsequent erosion of peat down slope from the transect. Site 7 was located along the edge of an apparently newly drained pool. The date of the breaching of this pool is not known but the physical condition of the pool walls and the health of the cushion community in 1983 suggested that this was relatively recent.

The corners of each quadrat were marked with 30$\mathrm{cm}$ steel pins. Each quadrat was vertically photographed using a wide angle lens with $35 \mathrm{~mm}$ colour slide film in late 1983 and again in 1988. These photographs were subsequently projected onto graph paper at scales of $1: 5$ or $1: 1.2$, depending on the complexity of the vegetation. The area of each individual taxon (species or life-form group) was determined either by direct counting of grid squares or by using a Tamaya PLANIX7 digital planimeter. In the degenerating cushion heath the cushion species were subdivided into vigorous ( $>80 \%$ live shoots) and non-vigorous $(<80$ $\%$ live shoots) classes.

Area figures were converted to percentages to remove any slight scale errors. All data were arcsine transformed. The difference between the values for percentage cover at the two sampling times was determined for each taxon and analysed using a paired $t$-test. The null hypothesis was that no change in cover values of individual taxa had occurred over the 5-yr period. Results from this analysis need to be treated with some caution because the quadrats were contiguous and as a consequence the cover data obtained are not independent. In general the effect of spatial dependence will be to reduce the apparent variation among replicates, thus leading to incorrect rejection of the null hypothesis. For this reason results were only considered significant at a level of $P<0.01$.

\section{Vegetation analysis}

37 drained pools of varying ages were located within the study area. 49 quadrats were located in these pools. Quadrat size was normally $5 \mathrm{~m} \times 5 \mathrm{~m}$, though occasionally $2.5 \mathrm{~m} \times 10 \mathrm{~m}$ quadrats were used due to pool shape. This area is greater than the minimal area required for sampling this vegetation type (Kirkpatrick \& Dickinson 1984). In each quadrat we collected presence/absence data for all vascular plants.
The data set was classified using the polythetic divisive technique implemented by the program TWINSPAN (Hill 1979). Cover of vegetation, bare mud and rock were estimated to the nearest $10 \%$. Vegetation cover of the quadrats in each classificatory group was compared by a one-way analysis of variance.

\section{Core analysis}

Two cores of $1030 \mathrm{~mm}$ depth were collected, using simple peat corers, from a cushion dam wall. The pool 1 $m$ up slope from the core site was of a similar depth. The first core was $50 \mathrm{~mm}$ in diameter. It compressed to a length of $525 \mathrm{~mm}$ on extraction. The core was subsequently cut in half lengthways and one half was used for cuticular analysis, The amorphous peat of the core was cut into contiguous $5 \mathrm{~mm}$ sections and cuticle extracted initially by soaking samples in dilute hydrogen peroxide, then clearing in nitric acid and potassium chlorate. Colloidal organic matter was removed with $10 \%$ potassium hydroxide. The cuticle was then washed, stained and mounted. This procedure resulted in degradation of some cuticle. To overcome this problem later samples were prepared by soaking in $10 \%$ chromic acid solution for 48 hours, then washing, staining and mounting. No pitting of cuticle was apparent using this technique.

Cuticle from the five dominant extant cushion species, Abrotanella forsteroides, Donatia novae-zelandiae, Dracophyllum minimum, Phyllachne colensoi, Pterygopappus lawrencei, was similarly prepared and used as a reference - cuticles of four of these species are illustrated in Gibson, Kiernan \& Macphail (1987).

In most samples at least 250 cuticle fragments were identified and counted, except where (in $15 \%$ of samples) there were fewer than 250 fragments and all were counted. The two Asteraceae species (A. forsteroides and $P$. lanrencei) had very similar cell wall detail but distinct leaf tip morphology, stomatal and trichome arrangements, so counting was continued until $100 \mathrm{frag}$ ments of these two species were positively identified.

The top $90 \mathrm{~mm}$ of the core consisted of a structured peat. This was divided into 10 -mm layers and dominance assigned on a species dry weight basis.

A second core was taken alongside the first with a $100 \mathrm{~mm}$ diameter corer. A basal sample, $10 \mathrm{~mm}$ in height from this core was used for radio-carbon dating. This sample was gently sieved through 60,599 , and $1405 \mu \mathrm{m}$ sieves. Approximately $0.15 \mathrm{~g}$ of wood was recovered and this material and the fine organic fraction $(60-599 \mu \mathrm{m})$ was used for dating. The samples were pre-treated by boiling in dilute hydrochloric acid and then filtered. The resulting date is reported as B.P. (i.e. radio carbon years before 1950 ) with \pm 1 standard deviation based on the mean of two counters. 


\section{Results}

Short-term dynamics

Mean cover values and mean differences in cover between the two sampling periods are shown in Table 1. In the low cover phase a significant decrease in percentage bare ground (which includes rock cover) was recorded at site l. At this site there was also a significant increase in the cover of Carpha rodwayi (a small sedge which forms small flat cushions). Some quadrats at site 2 recorded large increases in cover of the trailing shrub Cyathodes dealbata but this response was not consistent along the transect. No significant changes in $\operatorname{cover}$ (at $P$ $<0.01$ ) were recorded at this site.

At both sites individual cushions of Dracophyllum minimum were clearly perceived. Over the 5-yr period $12.5 \%$ of cushions disappeared at sitc 2 , and there was no recruitment at either site. Cushions at site 1 showed rates of diameter increases of 0 to $4 \mathrm{~mm} / \mathrm{yr} \quad(n=6)$ while the survivors at site 2 were growing at 0 to 7 $\mathrm{mm} / \mathrm{yr}(n=15)$.
Analysis of data from the two transects in the closed cushion heath showed no significant change in overall mean cover of the taxa at either site $(P>0.01)$ over the 5-yr period.

A detalled examination of the vegetation maps showed a much more dynamic situations than suggested by the overall figures for these sites. For the large cushions and cushion patches (areas $>5 \mathrm{~cm}^{2}$ ) there was evidence of both degradation and expansion occurring within all quadrats (Fig. 1). Commonly the same species was involved in both degradation and expansion within very short horizontal distances $(<30 \mathrm{~cm})$. Degeneration of the cushion species generally involved fragmentation rather than complete death, while expansion generally involved the coalescing of previously disjunct patches (Fig. I). The coalescing of patches resulted in minor lateral displacement of other species as did the general upward and outward growth of the entire mosaic over the five year period.

While dynamic changes in the larger cushions were apparent, careful analysis showed equally dynamic changes occurring in smaller cushions (area $<5 \mathrm{~cm}^{2}$ ).

Table 1. Mean total cover (\%) for species and species groups at each site in 1983 and 1988. Only taxa which occurred in at least three quadrats at one site were included. Where possible cushion species were divided into two subclasses, vigorous (with $>80 \%$ live shoots) and non-vigorous ( $<80 \%$ live shoots). Sites 1 and 2 - very open cushion heatl; sites 3 and 4 - closed cushion heath; sites 5 , 6 and 7 - degenerating cushion heath. Significant differences between years indicated by ${ }^{* 2}$ at $P<0.01$.

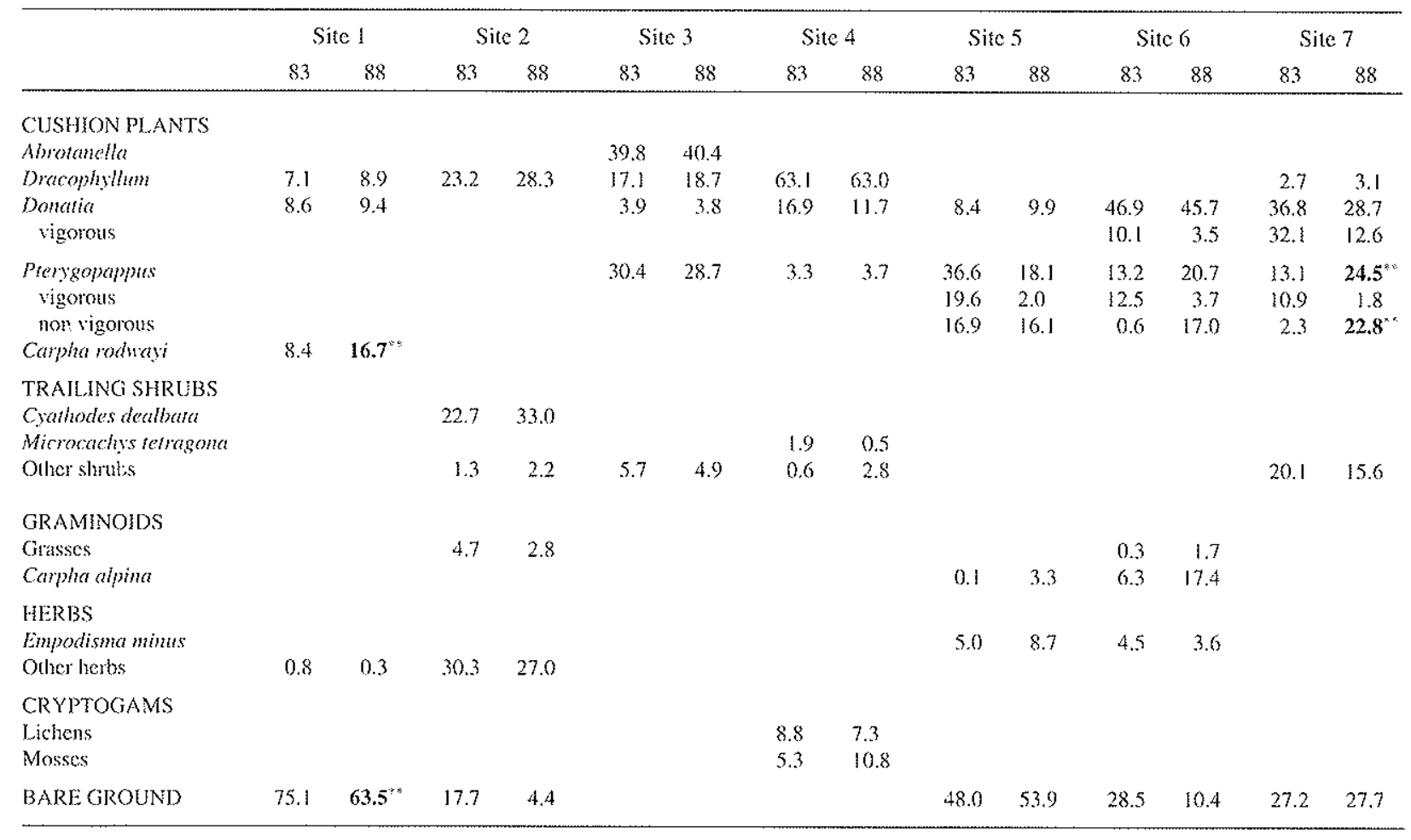


Table 2. Percentage survival of small $\left(<0.5 \mathrm{~cm}^{2}\right)$ and medium-sized $\left(0.5-5.0 \mathrm{~cm}^{2}\right)$ cushions in the closed cushion communify.

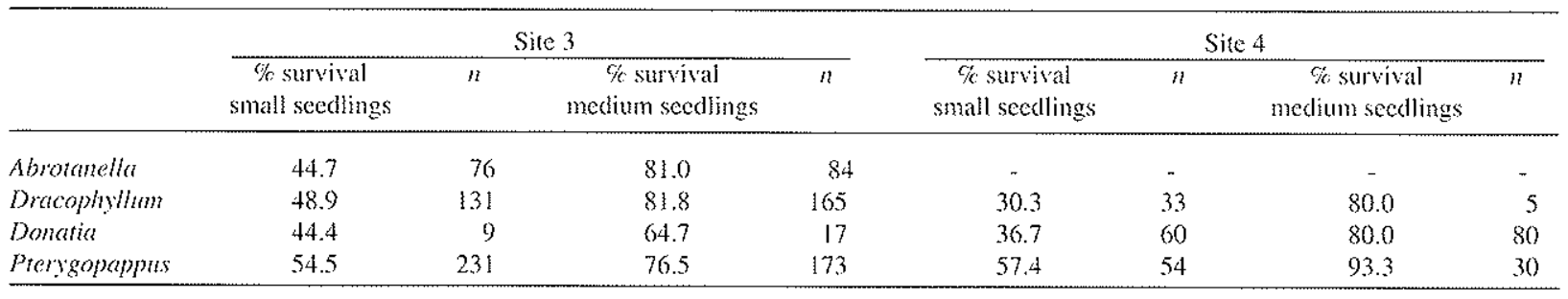

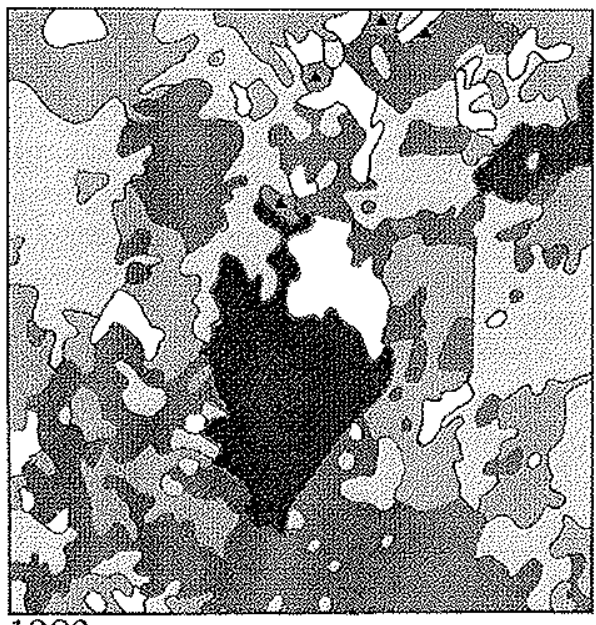

$\mathbf{a}$

1983

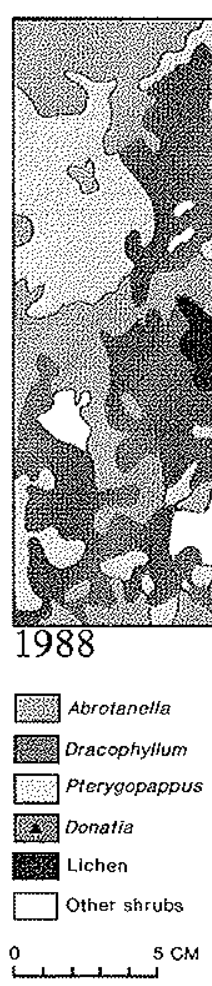

Fig. 1. Comparison of dominant plant species and life forms in a mature cushion community in (a) 1983 and (b) 1988.
Smaller individuals can arise by a variety of means including fragmentation of larger individuals, the coalescing of other species resulting in pinching off of small patches and germination of propagules. It is not possible to assign an origin to the smaller individuals found at the first sampling.

These smaller cushions were further subdivided into two classes, small $\left(<0.5 \mathrm{~cm}^{2}\right.$ in area) and medium $(0.5<$ area $<5 \mathrm{~cm}^{2}$ ). By overlaying the 1983 and 1988 maps it was possible to determine the survival patterns of these individuals (Table 2). Both sites showed similar patterns, with the medium sized cushions showing significantly higher survival $(65-93 \%$ vs $30-57 \%, P<0.01)$.

In the degenerating cushion heath (sites 5,6 and 7 ) only one site showed any significant change over the five years. At site 7 a significant increase $(P<0.01)$ in cover of $P$. lawrence $i$ was apparent but almost all of this was comprised of cushions in the non vigorous class (Table 1). Examination of individual maps showed the expansion of $P$. lawrence $i$ into areas formally occupied by $D$. novae-zelandiae and trailing shrubs. No other significant differences were found in cover for cushion species or bare ground at any of these sites.

\section{Vegetation}

The classification of the data set from the revegetating pool floors revealed three intergrading groups (Table 3). Species richness was found to increase with increasing plant cover. The classificatory groups break the data into what are presumed to be broad classes of age since pool drainage, with group one being the youngest (i.e. newly drained, mean vegetation cover $11.3 \%$ ) and group three the oldest (mean vegetation cover of $33.2 \%$, significantly greater than groups 1 and 2 at $P<0.001)$.

Species groups $A$ and $B$ arrive early in the presumed succession, followed by species group C; then, at a very late stage group D (Table 3 ). Mean species richness rose from 6.6 in group 1 , to 19.9 in group 2 , to 24.6 in group 3. The fully revegetated pools of group 3 are identical in species composition to the surrounding cushion heaths.

The ordering of species in this classification is related to soil moisture and drainage conditions. When the 
Table 3. Classification of quadrats from revegetating pools following drainage. Only taxa that occur at frequencies of at least $20 \%$ in one group are includied.

\begin{tabular}{|c|c|c|c|}
\hline \multirow[t]{4}{*}{ Specics } & \multicolumn{2}{|r|}{ Classiticatory group } & \multirow[t]{4}{*}{ Species group } \\
\hline & Group 1 & Group 3 & \\
\hline & 44100100100 & $|04334114+122222210| 22133213303321444311 \mid$ & \\
\hline & +3964351187 & {$[308798951027631082 \mid 54710865294395762642]$} & \\
\hline & $t+t+t$ & | & \\
\hline Isolepis sp. & 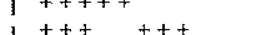 & + & \\
\hline Isolepis atucklandia & 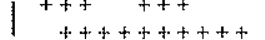 & $+\quad+4++1$ & \\
\hline Isolepis aff. productus & $\begin{array}{l}+++++++++ \\
++4++++\end{array}$ & $+++++++++++1++\quad+$ & \\
\hline Wyiophylhm pedunculatum & 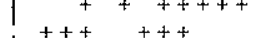 & $+\quad+++++++++\mid t+++++++t+t+$ & A \\
\hline Danthonia pauciffors & $\mid \begin{array}{ll}t+t+t+t+t+t+t \\
+t+t+t\end{array}$ & $|+t+t++t+t+t+t+t+t|+|+t+t+t+t+t+t+++t+t+|$ & \\
\hline Capha rodsayi & $1+t+t+t+t+t+t$ & 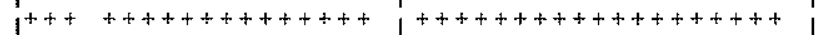 & \\
\hline Oreobolus pumitio & & 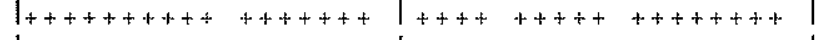 & \\
\hline Orities acicularis & + & $t+t+t+t+t$ & \\
\hline Gnaphalinm sp. & $\begin{array}{l}+ \\
t\end{array}+$ & $1+t+++t$ & \\
\hline Diosera arcui & $\begin{array}{l}+ \\
+ \\
+\end{array}$ & $+++++++++++++41+++4++++++++++$ & \\
\hline Gaimardiu fitzgeraldii & & 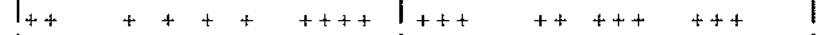 & \\
\hline Erigeron stellatus & +4 & $|+t+t+t \quad t+t+t+t+t|+t+t+t+t+t+t+t+t$ & \\
\hline Pleygopappus lawrencei & $t^{+}+t+t$ & 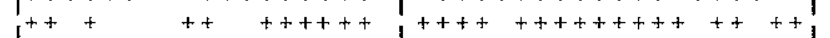 & B \\
\hline Domtia novte-zetandiar. & $++t$ & 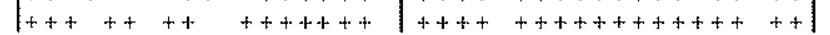 & \\
\hline Carpha alpina & $+7+$ & 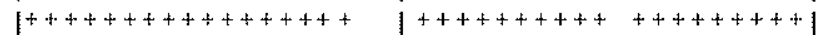 & \\
\hline Actinotus suffocata & + & $1++\quad++++++++++\quad 1$ & \\
\hline Mitrasacme archeri & $1+$ & $+t++t+t+t \mid+t+t+t+++t+++t+++1$ & \\
\hline Celmisia sasifraga & & 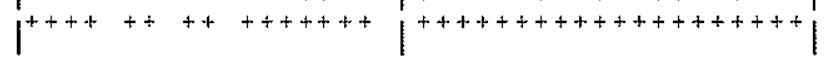 & \\
\hline Luzula spp. & & ++ & \\
\hline Acaena montana & & +++ & \\
\hline Agrostis spp. & 1 & $1+++$ & \\
\hline Etphrasia striata & & $1++++++$ & \\
\hline Herochloe fraseni & & ++++++4 & \\
\hline Helichysum backhousei & & $+1+t++t$ & c \\
\hline Euphrasia gibbsiat & & $1+t+t+t+t+t+t$ & \\
\hline Abrotanela scapigera & & $1+\quad++t++$ & \\
\hline Poatgumii & & $1+t++t+t+t+t+t+t \mid+t+t++t+$ & \\
\hline Gentionelle dicmensix & & t+t+t+t+t+t+t+t+t|t+t+t+t+t+t+t+t+1 & \\
\hline Brachycome sp. & & $|+t++t \quad+++++++|+t++++++++++$ & \\
\hline Epacris serpylifolia & & 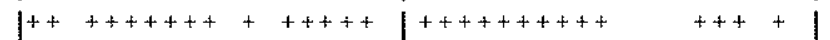 & \\
\hline Centrolepis momogyna & & $+t+t+t \quad+t+$ & \\
\hline Comprosma nitida & & $1++++++t+++++t$ & \\
\hline Astelia alpina & & $+++++++++++++4+t$ & \\
\hline Sprengetia incanata & & $+\mid++++t++++t+1$ & \\
\hline Tasmannia lanceolata & 1 & $+1++++++++++$ & \\
\hline Bellendenu montana & & ++ & \\
\hline Pentachondra pumila & & +++++++1 & $\mathrm{D}$ \\
\hline Microcachys tetragona & | & $+t+t+t+t+t$ & \\
\hline Helishrysum Iedifolium & 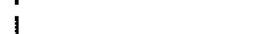 & $1+t+t+t+t+t$ & \\
\hline Dracomhylhm minimum & 1 & $t+t+t+++++t+t+t$ & \\
\hline Dislaspis cordifolia & & $|+t++++4+4+t+4+|$ & \\
\hline
\end{tabular}

pool is initially drained, the pool floor is generally comprised of a thin wet organic sludge. Three species of Isolepis are the initial colonizers. Isolepis aucklandicus and an unidentified Isolepis sp. are excluded in the final stage of the succession. However even when total vegetation cover is achieved, some small wet areas still exist in the cushion mosaic. This is indicated by the persistence of Isolepis aff. productus and Myriophyllum pedunculatum in the third classificatory group (Table 3 ).

Most of the shrub species belong to species group D and arrive late in the apparent succession. The interpretation of these patterns as a successional sequence remains tentative since no determination of the time of drainage of the pools was possible.

\section{Peat core}

Macrofossils found in peat are generally regarded as representing the local flora since water transport in these environments is minimal (Birks \& Birks 1980; Hill \& Gibson 1986). Their interpretation relies on the assumption of similar decomposition rates for cuticle of all major species.

This apparently holds for the Newdegate core, given the distribution of the major cushion species (Fig. 2). Five cushion species make up $99.9 \%$ of the recovered 


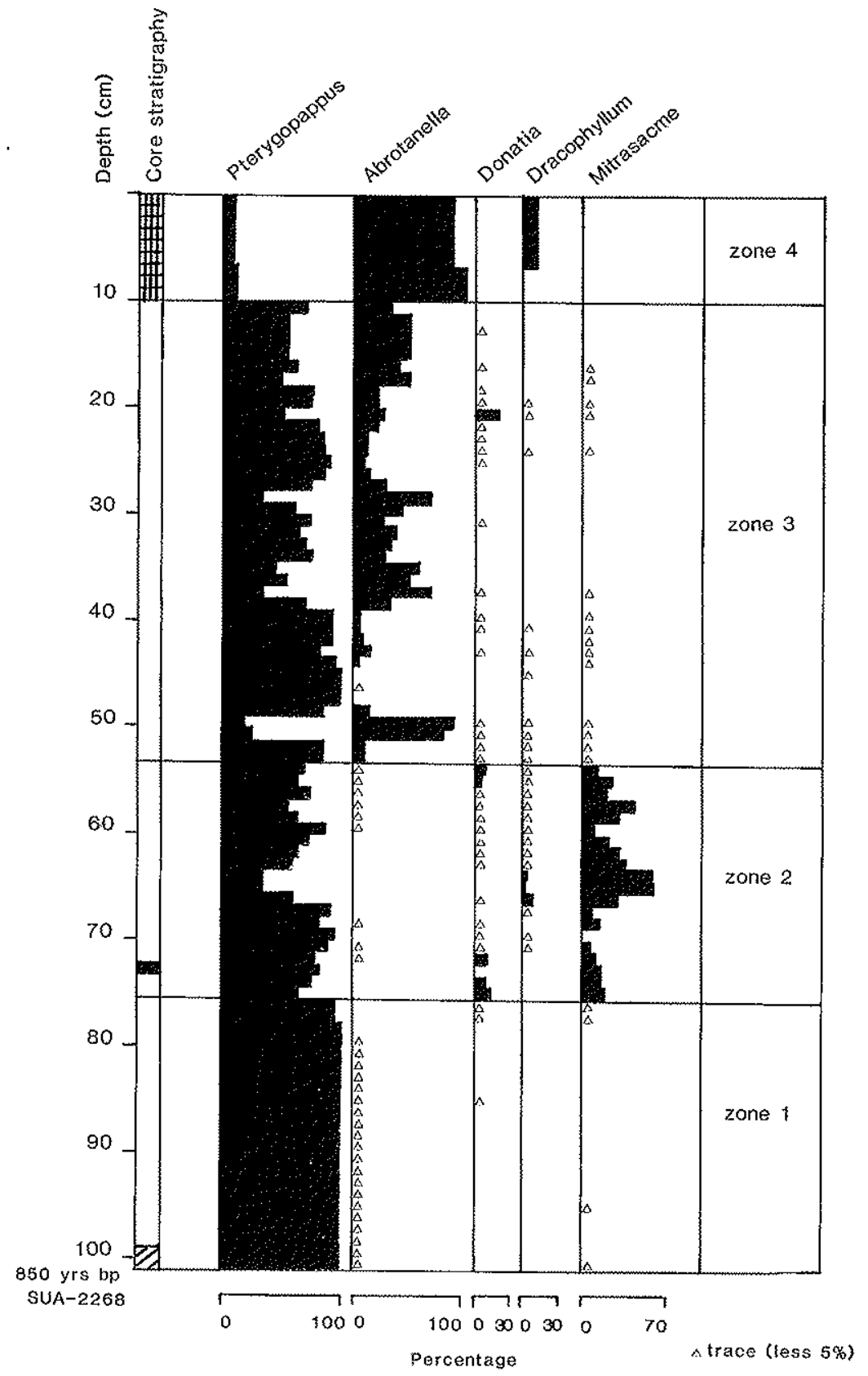

Fig. 2. Macrofossil diagram of material recovered from a $1030 \mathrm{~mm}$ core through a cushion dam at Newdegate Pass, Tasmania. cuticle. The lack of other species in the core probably results from the mode of formation of these peats. The cushion species themselves produce the peat by continuous vertical growth, the incorporation of old leaves and stems into the profile and the eventual compaction and decomposition of this material. Other species in this community tend to use the cushions peats as substrate. In the case of annuals most decomposition would occur on the surface (given the very slow growth rates of the cushions - Gibson 1990). While other shrubs could be expected to become incorporated into cushions peats from time to time, the proportion of this material would be very low given the very high shoot density of cushion species (ca. $100000 / \mathrm{m}^{2}$ - Gibson 1990) and the very short internodes of cushion species (up to 40 leaves / $\mathrm{mm}$ of shoot; see Gibson 1989).

The core was taken through a cushion dam wall. The cushion species D. novae-zelandiae, D. minimum, A. forsteroides and $P$. lawrence $i$ all occur in the present vegetation. The core was $1030 \mathrm{~mm}$ long. The top $90 \mathrm{~mm}$ consisted of a structured peat formed by undecayed cushion plant stems and leaves and, toward the bottom, 
adventitious roots. This section of the profile is dark reddish-brown in colour (5 YR 3/6). The rest of the profile consisted of an amorphous greasy peat of uniform brownish-black colour (5.5 YR 2/2).

Well-preserved cuticle was present throughout the entire profile. P. lawrencei and A. forsteroides were the major components while a fifth cushion plant Mitrasacme archeri, was locally abundant. D. novae-zelandiae and D. minimum appeared as minor components. Trace occurrences of an unidentified shrub species and a monocot were also recorded.

The macrofossil profile can be divided into four zones. Zone 1 at the base of the profile consists almost entirely of $P$. lawrence $i$ with a trace of A. forsteroides. Zone 2 is characterized by the occurrence of $M$. archeri and consistent occurrence of D. novae-zelandiae and $D$. minimum at low values. Near the bottom of zone 2 one sample had a large amount of charcoal almost co-incident with the rise in dominance of $M$. archeri. Given the position of the core from a dam wall, it is unlikely that the charcoal was water transported to the site, implying that either the cushion heath or the surrounding vegetation must have been burnt at this time. In zone 3 both $P$. lawrence $i$ and $A$. forsteroides are prominent with changing dominance. Zone 4 is the layer of structured peat and could not be considered analogous to the rest of the profile, which has undergone significant decomposition and compaction.

The chronology of this profile remains uncertain despite a basal radio-carbon date of $850 \pm 110 \mathrm{yr}$ B.P. (sample number - SUA 2268). Such rapid accumulation ( 8 years $/ \mathrm{cm}$ ) seems to contradict the measured growth rate of the cushion species $[4-14 \mathrm{yr} / \mathrm{cm}$ - Tasmania (Gibson 1990) and $1-3 \mathrm{yr} / \mathrm{cm}$ - in New Zealand (Bliss \& Mark 1974)] given the quite significant actions of decomposition and compaction during peat formation. Other data (Aaby \& Tauber 1975; Andrews et al. 1975; Heusser 1982; Tallis 1983) suggest that a rate of peat formation under the highly humic conditions prevalent in this alpine environment, might be expected to be of the order of $30-100 \mathrm{yr} / \mathrm{cm}$. Heusser (1982) working in very similar Donatia fascicularis Forst. peats in subalpine South America reported accumulation rates of 32 $-170 \mathrm{yr} / \mathrm{cm}$.

Examination of the fine material used for dating under a binocular microscope, revealed numerous fine root hairs. This may represent recent contamination of the sample by modern root material. It is also possible that significant humic acid accumulation has occurred above the bedrock. For these reasons it is suggested that this core is likely to represent a record considerably older than $850 \mathrm{yr}$.

\section{Discussion}

The climax vegetation in alpine Tasmania has generally been assumed to be coniferous heath (Jackson 1973). The analysis of the peat core fails to support this assertion. At this site it appears that a cushion community has been present for at least $850 \mathrm{yr}$. It appears likely that the growth habit (i.e. even vertical growth over large areas) of these species and the consequent influence on water table would result in an expansion of the cushion community over time, retarded only by localized changes in water table (Kirkpatrick \& Gibson 1984).

Although lacking a chronology for the revegetation study we believe these data are logically best interpretable as a successional sequence because of the floristic continuity between an assemblage of known primary colonisers and an assemblage identical with mature cushion heath. The most interesting aspect of this sequence is the lack of serial replacement of species as predicted by the classical succession model [Clements 1936; later called the facilitation model (Connell \& Slatyer 1977)]. This lack of pioneering species has also been reported from the Arctic by Wein \& Bliss (1973) and the high alpine cushion communities in New Zealand (Roxburgh, Wilson \& Mark 1988).

Connell \& Slatyer (1977) outline two other models of plant succession which they called tolerance and inhibition models. Under the tolerance model late and early colonist co-occur but final species composition will be determined by resource efficiency. Under the inhibition model once a species has become established it will continue to persist until it dies or is damaged. It will then be replaced either by the same or a different species. No difference in resource efficiency is assumed.

Data from the photopoint study fit neither of these models. In the mature cushion community while there was no directional change in total cover of the individual species over the $5-\mathrm{yr}$ period, examination of individual quadrats at a finer scale resulted in the recognition of considerable spatial variation over slort time periods and between different size individuals (e.g. Fig. 1).

Clearly the inhibition model does not hold since process of fragmentation and coalescence of cushions is occurring continuously across all quadrats. It has been argued elsewhere that significant resource partitioning is unlikely given the very close morphological convergence of the cushion species and the very poor nutrient status of these peats (Gibson 1989).

Our data and those of Gibson (1990) indicate that while significant competition is occurring in these communities no individual species has a continuous competitive advantage over any other and that community stability (at least over time spans of $850 \mathrm{yr}$ ) appears to be 
maintained by non-equilibrium processes. Our data most closely fits a model of temporal enviromental fluctuations with continuous competition (Chesson \& Case 1986; Gibson 1990).

The dynamic patterns of change seen within individual quadrats contrast with the very small changes mapped by Roxburgh, Wilson \& Mark (1988) in an undisturbed high-alpine cushion community in New Zealand over a 2 -yr period. This difference may result from slower growth rate in the New Zealand alpine environment or may indicate other processes are determining community composition and stability in these areas.

Acknowledgements. We thank Dr. R. S. Hill for his assistance with the cuticular analysis. This work was undertaken on a Commonwealth Postgraduate Research Award.

\section{References}

Aaby, B. \& Tauber, H. 1975. Rates of peat formation in relation to degree of humification and local environment, as shown by studies of a raised bog in Denmark. Boreas 4 : $1-17$.

Andrews, J. T., Carrara, P. E., King, F. B. \& Stuckenrath, R. 1975. Holocene environmental changes in the alpine zone, northern San Juan Mountains, Colorado: evidence from bog stratigraphy and palynology. Quat. Res. (N.Y.) 5: 173197.

Birks, H. J. B. \& Birks. H. H. 1980. Quatemary paleoecology: Edward Arnold, London.

Bliss, L. C. \& Mark, A.F. 1974. High alpine environments and primary production on the Rock and Pillar Range, Central Otago, New Zealand. N. Z. J. Bot. 12: 445-483.

Buchanan, A. M., McGeary-Brown, A. \& Orchard, A. E. 1989. A census of the vascular plants of Tasmania. Tasmanian Herbar. Occ. Publ. 2: 1-82.

Chesson, P. L. \& Case. T. J. 1986. Overview: Non equilibrium theories: Change, variability, history and coexistence. In: Diamond, J. \& Case, T. J. (eds.) Community ecology; pp. 229-239. Harper \& Row, New York.

Clements, F. E. 1936. Nature and structure of climax. J. Ecol.
24: 252-284.

Connell, J. H. \& Slatyer, R. O. 1977. Mechanisms of succession in natual communities and their role in community stability and organisation. Am. Nat. 11 1; 1119-1144.

Gibson, N. 1989. A study on the biology of four Tasmanian cushion species. Ph.D. thesis, University of Tasmania, Hobart, Tasmania.

Gibson, N. 1990. The environment and primary production of cushion species at Mt Field and Mt Wellington, Tasmania. Austr. J. Bot. 38: 229-243.

Gibson, N., Kiernan, K. \& Macphail, M. K. 1987. A cossil bolster plant from the King River, Tasmania. Pap. Proc. R. Soc. Tasmania 12 1: 35-42.

Heusser, C. J. 1982. Palynology of cushion bogs of the Cordillera Pelada, Province of Valdivia, Chile. Quat. Res. (N.Y.) 17: 71-92.

HiII, M. O. 1979. TWINSPAN - A FORTRAN program for the arranging of malivariate data in ordered two way tables by classification of individuals and attributes. Cornell University, New York.

Hill, R. S. \& Gibson, N. 1986. Distribution of potential macrofossils in Lake Dobson, Tasmania. J. Ecol. 74: 373384.

Jackson, W. D. 1973. Vegetation of the Central Platean. In: Banks, M. R. (ed.) The Lake Cotmtr, pp. 61-85. Royal Society of Tasmania, Hobart.

Kirkpatrick, J. B. 1983. Treeless plant communities of the Tasmanian alpine floras. Pap. Proc. R. Soc. Tasmania 12: $61-77$.

Kirkpatrick, J. B. \& Dickinson, K. J. M. 1984. The impact of fire on Tasmanian alpine vegetation and soils. Austr. $J$. Bot. 32: 613-629.

Kirkpatrick, J. B. \& Gibson, N. 1984. Dynamics of a Tasmanian bolster heath string fen. Vegetatio $58: 71-78$.

Kirkpatrick, J. B., Minchin, P. R. \& Davies, J. B. 1985. Floristic composition and macroenvironmental relationships of Tasmanian vegetation containing bolster plants. Vegetatio 63: 89-96.

Roxburgh, S. H., Wilson, J. B. \& Mark, A. F. 1988. Succession atter disturbance of a New Zealand high-alpine cushionfield. Arct Alp. Res. 20: 230-236.

Tallis, J. H. 1983. Changes in wetland communities. In: Gore, A. J. P. (cd.) Ecosystems of the World 4A, Mires: Swamp, bog, fen and moor, pp. 311-347. Elsevier, Amsterdam.

Wein, R. W. \& Bliss, L. C. 1973. Changes in arctic Eriophonum uussock communities following fire. Ecology 54: 81-88.

Received 5 February 1992; Revision received 22 April 1992; Accepted 26 June 1992; Final revision received 28 July 1992. 